\title{
A FIVE YEAR RETROSPECTIVE SURVEILLANCE; MONITORING AND EVALUATION FOR THE REGIONAL TUBERCULOSIS CONTROL PROGRAMME IN MERSIN, TURKEY, 2004-2008
}

\author{
A. Öner Kurt' ${ }^{1}$, Tayyar Şaşmaz', Resul Buğdaycı' ${ }^{1}$, Seva Öner ${ }^{1}$, Gülçin Yapıcı ${ }^{1}$, Özdemir Özdemir ${ }^{2}$ \\ ${ }^{1}$ Department of Public Health, Mersin University Faculty of Medicine, Mersin, Turkey \\ ${ }^{2}$ General Practitioners, Tuberculosis Dispensary of Mersin, Mersin, Turkey
}

\section{SUMMARY}

Aim: The aim of this study is to identify and evaluate problems in regional tuberculosis control studies, using an international tuberculosis indicator. Methods: In this retrospective cohort study, the records of a total of 1,776 patients diagnosed with tuberculosis, followed up and treated from 2004-2008 in Mersin were evaluated. Indicators recommended by the World Health Organization were used as assessment criteria. Descriptive statistics were used to summarize data. The Mantel-Haenszel test was used for calculation of the risk between urban/rural, and between male/ female which were in different age groups.

Results: During the five year period, new case notification rates were reduced and tuberculosis risk shifted to advanced age groups in our region. Tuberculosis development risk increased two-fold among males $(p<0.001)$. One-fifth of the tuberculosis cases had been diagnosed without sputum smears. Sputum microscopy was not done at the end of the initial phase in one-fifth of patients. During the five-year follow-up period, tuberculosis treatment success rate increased from $83 \%$ to $91 \%$ and cure rate increased from $49 \%$ to $67 \%$. The death rate, treatment failure rate, default rate, and transmission rate decreased, and the directly observed treatment implementation increased.

Conclusion: Improvements were seen in diagnosis and treatment indicators beginning from 2006; the year when the directly supervised treatment application started. However, use of sputum smear microscopy is inadequate for the diagnosis and treatment of tuberculosis. Tuberculosis control studies should be monitored and evaluated using a tuberculosis indicator.

Key words: directly observed treatment, epidemiology of tuberculosis, tuberculosis control programme, tuberculosis evaluation/monitoring criteria

Address for correspondence: A. Ö. Kurt, Department of Public Health, Mersin University Faculty of Medicine, 33169 Mersin, Turkey. E-mail: onerkurt@mersin.edu.tr

\section{INTRODUCTION}

Global efforts to control tuberculosis (TB) were reinvigorated in 1991, when a World Health Assembly resolution recognized TB as a major global public health problem (1). The World Health Organization (WHO) declared tuberculosis a global emergency in 1993 (2). The latest assessment of the global burden of TB in 2009 estimate 9.4 million incident cases, 14.0 million prevalent cases, and 1.7 million deaths (3). Globally, TB incident rates peaked at 142 cases per 100000 population in 2004. There were an estimated 139 incident cases per 100000 population in 2007 and 137 cases per 100000 population in 2009 (3-5). However, global incidence rates have been declining since 2004 (3). Incidence rates are falling in five of the six WHO regions (with the exception of the European region, where rates remain relatively stable). In Turkey, which is classified in the European region by WHO, the incidence rate declined from 33/100000 to 29/100000 beginning from 2005 to 2009 . Turkey is one of 36 countries which achieved the target of the World Health Assembly by detecting $70 \%$ of smear positive cases with directly observed treatment
(DOTS) programmes and treated $85 \%$ of them successfully (5). The treatment success was $86 \%$ in the world, $66 \%$ in Europe and $92 \%$ in Turkey in 2008 (3).

Routine monitoring of TB control is crucial in order to understand trends in the TB epidemic and progresses in TB control (4-5). Following are the main indicators used to monitor the progress in TB control up to 2015: trends in incidences, prevalence and mortality, treatment success rate and the case detection rate for all forms of TB. Use of the case detection rate for smear positive TB should be phased out (3). The overall purpose of monitoring and evaluation is to measure programme effectiveness, identify problem areas, take note of the lessons learned, and improve the overall performance. The indicators are routinely calculated by TB control programmes at district, regional, and national levels. They are used to monitor progress towards the achievement of the national targets for case detection and treatment outcomes, and also to monitor programme quality and effectiveness (6).

TB has been controlled over the years at global and national levels with the programmes launched; however, there are differences between regions with regards to TB indicators recorded. 
Due to epidemiological properties of the disease, tuberculosis control requires conducting of long-standing programmes, and reporting of programme results with globally, nationally and locally measurable and comparable indicators (7). The aim of this study was to determine TB trends, to evaluate effectiveness of regional TB control studies and to detect problems in the control studies carried out from 2004-2008 in Mersin, which is located in the southern part of Turkey.

\section{METHODS}

Data for this study was taken from the project: 'Evaluation of study records of TB dispensary in the Mersin province from 2004-2008' (21 May 2009), planned by the Department of Public Health, the Mersin University Medical Faculty, and the Local Health Authority of Mersin.

\section{Study Type and Study Period}

Our study is a retrospective cohort study. Data was collected in July and August of 2009. However, treatment outcomes of patients whose treatment had not been terminated were completed in July and August 2010.

\section{Study Population and Data Collection}

The Mersin province is located in the Mediterranean region of Turkey with a population of 1.5 million. There is approximately $321 \mathrm{~km}$ distance between the eastern and western borders of the province (8-13). The diagnosis and treatment of TB patients in Mersin were conducted in four distinct TB dispensaries. These four dispensaries are located in Tarsus, a centre in the eastern part of the province and in Silifke and Anamur in the West. The records of all patients diagnosed with TB and treated in these dispensaries between 01 January 2004 and 31 December 2008 were taken as the study population. A total of 1,846 patient applications were entered into the computer. Fifty-three of them were excluded from the data set as they were diagnosed with something else than TB. 17 patients were recorded in two distinct dispensaries at the same time, therefore one of them was excluded from the study. In our study, dispensary records of 1,776 TB patients were evaluated.

In Turkey, treatment, follow ups and recording of all $\mathrm{TB}$ patients are conducted by TB dispensaries. This is important for recording and for records accuracy. Sputum smear and radiology are available for TB diagnosis in TB dispensaries in Turkey (14). DOTS for TB control began in June 2006 in Mersin and throughout the rest of Turkey (15).

\section{Statistical Analyses}

The analyses were performed with data sets and the standards defined by WHO (5). In our study, indicators recommended by WHO were used for evaluation of the TB control programme applied in our region (6). The number of TB cases obtained from the records was used for calculation of the annual case notification rates (CNR). For demographic data, mid-year household population number obtained from the Local Health Authority in Mersin was used. The populations according to years were as follows: $1,522,934 ; 1,551,176 ; 1,581,446 ; 1,608,259$ and $1,546,391(8-12)$.

In addition to these indicators, the distribution of new CNR according to residential area, gender and age groups of the previous five years was calculated. The risks between urban/rural and male/female for new cases were calculated by the Mantel Haenszel Test. Whether the odds ratio (OR) values obtained as a result of the Mantel Haenszel Test differed significantly was evaluated with the Breslow-Day statistics. The risk between the age groups for new cases was calculated by the Chi-Square Linear-by-Linear Association analyses. In addition to this, the median age distributions of cases according to years were calculated individually for both males and females.

\section{RESULTS}

In this study, records of $1,776 \mathrm{~TB}$ patients in the provincial centre and suburbs of the Mersin province during a five year period between 2004 and 2008 were evaluated. The patient numbers were 355, 389, 398, 321 and 313 respectively between 2004 and 2008.

\section{Notification and Diagnosis}

A reduction in CNR was recorded in Mersin between 2004 and 2008. As to the new CNR, after a slight increase observed in 2005 and 2006 compared to 2004, gradual decrease was observed in 2007 and 2008. Besides, the new smear positive pulmonary TB (PTB) cases notification rate was seen to rise and peak and thereafter decline in an undulating pattern in 2006 (Table 1).

New CNR reduced both in urban and rural areas and in both genders in a five-year period. An increase in CNR in those aged over 55 years was compensated by the declining trend in childhood, adolescence and middle age groups (Table 2).

The median age of new TB cases was changed from 31 to 36 across the whole group, and from 33 to 37 in males, and from 27 to 35 in females. It was found that new case TB rate increased significantly with age every year $\left(2004: \chi^{2}=23.393 \mathrm{p}=0.001 ; 2005\right.$ : $\chi^{2}=44.959 \mathrm{p}=0.001 ; 2006: \chi^{2}=43.633 \mathrm{p}=0.001 ; 2007: \chi^{2}=48.282$ $\left.\mathrm{p}=0.001 ; 2008: \chi^{2}=59.098 \mathrm{p}=0.001\right)$ and there was a positive correlation between age and TB rate in all years (Table 2).

A similar rate of new TB cases was detected in both urban and rural areas for all years and the OR value did not change significantly over the years $(p=0.257)$. In our region, the TB development risk was estimated to be the same in urban and rural areas between 2004 and 2008 (in homogenous group, Mantel-Haensel Test; OR=1.0, 95\% CI, 0.863-1.112, $\mathrm{p}=0.810$ ). For each year, TB was detected as being more frequent among males compared to females and male/female OR values were found not to change significantly $(\mathrm{p}=0.581)$. For all years, the TB rate was estimated to be twice as high in males compared to females (in homogenous group, Mantel-Haensel Test; OR=2.0, 95\% CI, 1.783-2.195, $\mathrm{p}=0.001$ ). The yearly distribution of TB risk related to residential area and gender is given in Table 3 .

The number of new adult smear positive TB cases increased considerably in 2006; however, it declined again in 2008. In contrast, the new PTB cases with no smear results decreased in 2006 and increased again in 2008. A reduction was seen in the sputum conversion rate at the end of the initial phase of treatment 
Table 1. Indicators for TB control programme outcomes in Mersin, 2004-2008 cohorts

\begin{tabular}{|c|c|c|c|c|c|c|}
\hline & Indicators/Years & 2004 & 2005 & 2006 & 2007 & 2008 \\
\hline \multirow{10}{*}{ 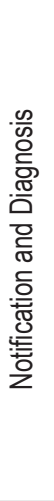 } & CNR: New cases $^{a}$ & 21.7 & 23.6 & 22.3 & 17.4 & 17.8 \\
\hline & CNR: New and relapse cases ${ }^{\mathrm{a}}$ & 23.0 & 24.5 & 23. 8 & 19.3 & 19.2 \\
\hline & CNR: All cases ${ }^{\mathrm{a}}$ & 23.3 & 25.1 & 25.2 & 20.0 & 20.2 \\
\hline & CNR: New smear-positive pulmonary TB cases $^{a}$ & 9.4 & 10.4 & 14.2 & 9.5 & 8.9 \\
\hline & 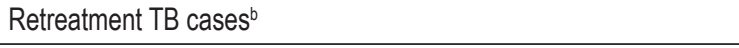 & 5.6 & 3.9 & 7.8 & 10.9 & 8.6 \\
\hline & New extrapulmonary TB cases ${ }^{b}$ & 26.4 & 24.6 & 22.7 & 27.1 & 26.9 \\
\hline & New pulmonary TB cases with no smear result ${ }^{b}$ & 29.6 & 31.9 & 8.1 & 13.2 & 23.4 \\
\hline & New adult smear-positive TB cases ${ }^{b}$ & 60.9 & 59.3 & 84.2 & 75.1 & 68.2 \\
\hline & Sputum conversion rate at the end of the initial phase of treatment ${ }^{b}$ & 70.6 & 57.1 & 71.4 & 68.0 & 63.5 \\
\hline & New TB cases with no smear conversion result ${ }^{b}$ & 25.2 & 38.0 & 18.3 & 17.7 & 21.9 \\
\hline \multirow{9}{*}{ 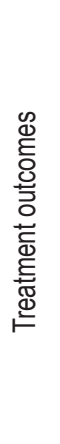 } & Treatment success rate $^{b}$ & 83.2 & 85.1 & 88.8 & 92.8 & 91.2 \\
\hline & Cure rate $^{b}$ & 49.7 & 40.4 & 67.4 & 64.7 & 67.2 \\
\hline & Treatment completion rate ${ }^{b}$ & 33.6 & 44.7 & 21.4 & 28.1 & 24.1 \\
\hline & Death rate ${ }^{b}$ & 5.6 & 3.7 & 1.3 & 1.9 & 1.5 \\
\hline & Treatment failure rate $^{b}$ & 4.2 & 6.2 & 4.1 & 3.9 & 2.9 \\
\hline & Default rate $^{b}$ & 2.1 & 2.5 & 2.7 & 0.0 & 1.5 \\
\hline & Transfer out rate ${ }^{b}$ & 4.9 & 2.5 & 3.1 & 1.3 & 2.9 \\
\hline & Retreatment failure rate (chronic TB rate) ${ }^{b}$ & 11.1 & 0.0 & 3.9 & 0.0 & 0.0 \\
\hline & Patient under direct observation of therapy ${ }^{b}$ & 0.0 & 0.0 & 35.3 & 86.9 & 97.1 \\
\hline
\end{tabular}

a per 100000 population; $\mathrm{b} \%$

and new TB cases with no smear conversion result rate in the five-year period (Table 1).

\section{Treatment Outcomes}

In our study, it was observed that the treatment success rate and cure rate increased in the five years. During this period, a reduction was seen in the treatment completion rate; death rate, treatment failure rate, default rate, and transfer out rate (Table 1, Fig. 1). Among retreated cases, the number of treatment failures was one in 2004 and one in 2006. However, apart from the aforementioned periods, all re-treated patients were seen to make a complete recovery. In our region, the number of patients under DOTS rate was zero in 2004 and 2005, but increased after 2006 (Table 1).

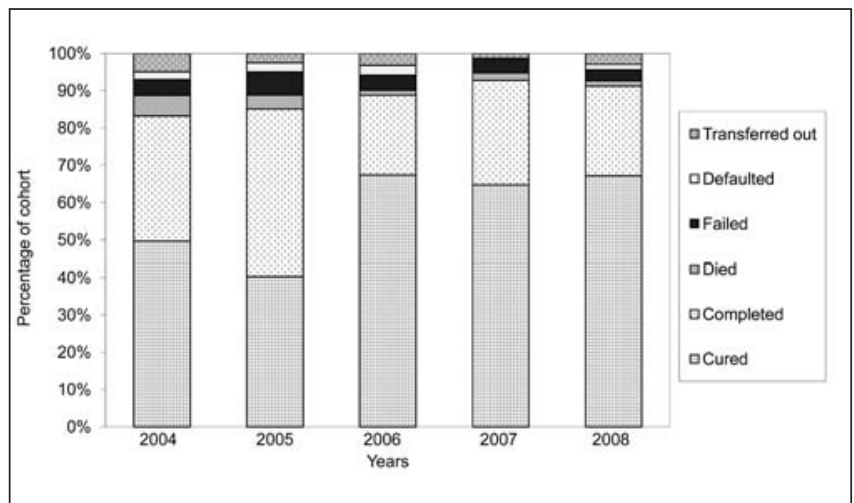

Fig. 1. Treatment outcomes for patients in Mersin, 2004-2008 cohorts.

\section{DISCUSSION}

\section{Notification and Diagnosis}

In the 2010 WHO report, the TB notified new and relapse rate was reported to have risen to $85 / 100000$ from $79 / 100000$ globally. However, it decreased to 38/100000 from 41/100000 in the European region and to 24/100000 from 28/100000 in Turkey between 2005 and 2008 (3). In the study by Dye (16) evaluating data from 134 countries, CNR was reported to decrease over time, and Falzon (17) states 47 and 48/100000 in 2004 and 2005, respectively, in the same region; 29 and 29/100000 in the Balkans including Turkey. CNR detected in our study region is lower than that one of the world, Europe and Turkey, and shows a declining trend alike in Turkey and Europe. The decline in CNR in Mersin between 2004 and 2008 indicates that the incidence of TB have generally decreased in our region.

Balbay et al. (18) reported that a ratio of new TB cases is similarly in urban and rural areas and Akgün et al. (19) reported that it was twice as high in urban areas compared to rural areas. In our study, the new TB case rate was found to be similar to that of Balbay et al. in urban and rural areas. In our region, the fact that the risk of developing TB was similar in urban and rural areas between 2004 and 2008, and the new CNR decline over the years, indicates that this problem is common for both urban and rural areas and that TB control studies were conducted with the same amount of effectiveness in the whole region.

The TB male/female ratio between 2005 and 2009 is reported as 1.8 and 1.8, 2.1 and 2.4, 2.7 and 2.7 globally, in Europe and in Turkey, respectively (3), and an average 1.8 in the Balkans between 1995 and 2005 (17). In previous studies, the male/fe- 
Table 2. Distribution of TB case notification rate according to years, residential area, gender and age group in Mersin, 2004-2008 cohorts (per 100000 population)

\begin{tabular}{|l|c|c|c|c|c|}
\hline Variables & 2004 & 2005 & 2006 & 2007 & 2008 \\
\hline Residential area \\
\hline Urban & 20.6 & 24.2 & 22.3 & 17.5 & 17.8 \\
\hline Rural & 27.1 & 20.6 & 22.0 & 16.9 & 17.6 \\
\hline Gender \\
\hline Male & 29.4 & 32.4 & 29.2 & 22.0 & 23.3 \\
\hline Female & 13.9 & 14.7 & 15.2 & 12.8 & 12.3 \\
\hline Age groups & \multicolumn{5}{|l}{} \\
\hline 0-4 & 2.6 & 5.2 & 0.0 & 2.5 & 0.8 \\
\hline $5-14$ & 5.3 & 5.6 & 5.5 & 1.7 & 2.5 \\
\hline $15-24$ & 32.4 & 27.8 & 31.4 & 22.2 & 19.4 \\
\hline $25-34$ & 27.6 & 29.1 & 25.0 & 20.0 & 25.5 \\
\hline $35-44$ & 23.9 & 31.5 & 29.1 & 21.9 & 21.7 \\
\hline $45-54$ & 28.6 & 33.2 & 29.5 & 26.9 & 19.6 \\
\hline $55-64$ & 28.1 & 28.8 & 15.0 & 26.2 & 34.7 \\
\hline $65+$ & 19.9 & 31.0 & 42.5 & 22.7 & 27.1 \\
\hline Total & 21.7 & 23.6 & 22.3 & 17.4 & 17.8 \\
\hline
\end{tabular}

male ratio was reported to be between 2.0 and $2.8(18,20-23)$. Also in our study, twice as high risk of TB in males compared to females is similar to other published reports and studies. We believe that reason for higher prevalence of TB in males arises from the different biological factors and social roles of males and females.

In studies investigating the distribution of TB according to age groups, a reduction in incidence rates was seen in younger age groups and increased in the elderly $(14,20,22,24-26)$. In our region, TB decreases in childhood compared to other age groups and the median age of new TB cases increase in those years may indicate decrease of the infection in childhood and adolescence. The reduction in childhood suggests that TB infection risk decreases in this age group in our region (27).

In recent years, new smear positive pulmonary TB CNR obtained in our study is in decline - a trend similar to the global one. (3). New smear positive pulmonary TB CNR's peaks in 2006, a possible consequence of the DOTS initiation in Turkey and in our region and TB control studies' being conducted with a novel policy after 2006. According to this data, we can state that treatment effectiveness of TB increased and infectiousness of the disease decreased in Mersin between 2004 and 2008.

In our study, it is seen that one-fifth of TB cases were diagnosed without making a sputum smear and sputum microscopy was not studied at the end of the initial phase in one-fifth of the cases diagnosed. However, out of the total sputum microscopies performed $40 \%$ of the cases remain positive after the initial phase. Despite the fact that sputum samples should be examined from all patients under suspicion of PTB (28) if the microscopy laboratory is available, smear positive cases should constitute at least $65 \%$ of PTB cases in adults (6). However, it was observed that these ratios could not be achieved in our region. In our study, a new PTB case with a no smear result rate is higher than that recorded in Turkey $(32.9 \%, 21.4 \%, 16.2 \%, 11.2 \%, 11.4 \%$ for $2004-2008$, respectively) $(7,14)$. Therefore, it can be stated that, in terms of bacteriological examination, there is a problem in our region as some cases had been diagnosed only radiologically without the support of sputum microscopy. An increase of sputum microscopy use in TB diagnosis after 2006 may be attributed to the effect of DOTS implementation.

While most of the new smear positive PTB patients should become negative after two or three months of therapy (6), it may be concluded that the reason for approximately $40 \%$ of the cases staying positive may be due to poor treatment compliance, and a lack of sputum samples obtained at the end of initial phase because of technical or staff problems and due to a poor DOTS.

Table 3. Evaluation of TB risk for new cases according to residential area and gender in Mersin, 2004-2008 cohorts

\begin{tabular}{|c|c|c|c|c|c|c|}
\hline & \multicolumn{6}{|c|}{$95 \%$ confidence interval for mean } \\
\hline & Years & OR & Lower bound & Upper bound & $P$ value $^{a}$ & $P$ value ${ }^{b}$ \\
\hline \multirow{6}{*}{ 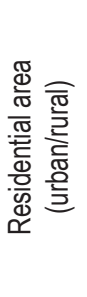 } & 2004 & 0.8 & 0.582 & 1.000 & 0.048 & \multirow{6}{*}{0.257} \\
\hline & 2005 & 1.2 & 0.877 & 1.570 & 0.281 & \\
\hline & 2006 & 1.0 & 0.765 & 1.348 & 0.916 & \\
\hline & 2007 & 1.0 & 0.751 & 1.429 & 0.830 & \\
\hline & 2008 & 1.0 & 0.734 & 1.407 & 0.925 & \\
\hline & Total & 1.0 & 0.863 & 1.122 & 0.810 & \\
\hline \multirow{6}{*}{ 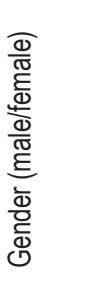 } & 2004 & 2.1 & 1.682 & 2.274 & 0.001 & \multirow{6}{*}{0.581} \\
\hline & 2005 & 2.2 & 1.775 & 2.765 & 0.001 & \\
\hline & 2006 & 1.9 & 1.538 & 2.390 & 0.001 & \\
\hline & 2007 & 1.7 & 1.344 & 2.185 & 0.001 & \\
\hline & 2008 & 1.9 & 1.484 & 2.439 & 0.001 & \\
\hline & Total & 2.0 & 1.783 & 2.195 & 0.001 & \\
\hline
\end{tabular}


In our study, new extrapulmonary TB (EPTB) case rate is above the recommended $10-15 \%$ ratio (6) in the world in general and Europe in particular, and below the rate showed in Turkey (3). High EPTB case rate in our region with no noticeable reduction over the years points to the need for EPTB research here.

\section{Treatment Outcomes}

In our study, treatment success rate recommended for determining quality and efficacy of the national TB control programme (6) has been above both $85 \%$, which is the recommended threshold level (5), and the mean value for the world (3) since 2005. Further, the treatment rate has gradually increased over the years. This condition indicates capacity of the TB control programme for securing the patient during a course of chemotherapy and the success of treatment process.

The cure rate accepted as safer and more valuable indicator than treatment success rate (6) was approximately $80 \%$ in the world at large, $60 \%$ in Europe and Turkey between 2005 and 2008 , and has been noted to increase since (3). In our study, it was observed that the cure rate is higher than in Europe and Turkey, lower than in the world at large and with similar increase in the period of the study. In Mersin from 2004 to 2008, the reduction in the death rate, treatment failure rate, default rate, transfer out rate and increase in the DOTS implementation had significant effects on the increase of treatment success and cure rate.

Treatment completion rate was reported to be $7 \%$ in the world between 2005 and 2008 and remained constant, reduced to $8 \%$ from $13 \%$ in Europe and to 33\% from $44 \%$ in Turkey, respectively (3). In our study, treatment completion rate in Mersin was higher than the value in the world and Europe and lower than that of Turkey. Again, in our Mersin study, while treatment completion rate declined during the five-year period, the cure rate increased, which is important in terms of indicating increase in the number of microbiological analyses rate at the beginning and end of therapy.

The percentage of basal value of the total negative results (death rate, treatment failure rate, default rate) for the new smear positive cases was $15 \%(6)$. In our study, the sum of three indicators is below the value of the world, Europe and Turkey (3) and the recommended basal limit. The sum of negative results reduction to half from $2004(12 \%)$ to $2008(6 \%)$ indicates increase of both treatment success and the success of DOTS applications in our region.

Progress in DOTS implementation is reported to be $83 \%$, $89 \%, 93 \%, 94 \%$ and $46 \%, 59 \%, 67 \%, 75 \%$ globally and in Europe, respectively, between 2004 and 2007 (5). The DOTS ratio in Turkey was reported to be $94.2 \%, 95.9 \%$ for 2007 and 2008, respectively (14). The DOTS rate was zero in our region during 2004 and 2005 as the DOTS implementation did not start before 2006 and reached $97 \%$ in 2008 . These outcomes were interpreted as an achievement of the DOTS implementation recommended by the Ministry of Health and conducted in Mersin also. Positive outcomes in the diagnosis and treatment observed from 2006 are significant in terms of showing the effect of DOTS implementation versus the traditional programme (29).

The national TB control program and policy prepared by the Ministry of Health in light of the recommendations of WHO was accurately applied in Mersin (14). As records of all TB patients in our region could be accessed, the evaluation of the program held in Mersin and its suburbs may give us an idea regarding TB control studies in Turkey and the results obtained from our region may be generalized for the whole of the country.

\section{Limitations of the Research}

The retrospective nature of the study is a limitation as not all TB cases are registered by health institutions for diagnosis and treatment. Though the same physicians were participating in the study, their differing attitudes and systems in terms of producing medical records may have lead to insufficient accuracy. Additionally, the technical staff carrying out smear microscopic examinations may have interpret the results differently.

\section{CONCLUSION}

In conclusion, our study demonstrated that a sputum smear microscopy is inadequately used for the diagnosis and treatment of tuberculosis. Furthermore, the increase in cure rates over the years is insufficient. In order to solve this problem, the ratio of sputum smear should be increased up to $100 \%$, especially when diagnosing PTB in adults and follow up of cases. In our study, it was observed that we face considerable problems in TB control studies. In the light of our findings, we recommend that TB control studies be monitored and evaluated employing the recommended tuberculosis indicators.

\section{Acknowledgements}

We would like to thank to S. Sahip, A. Tol, K. Erkan, M.D.; Z. Eroglu, S. Akyuz, M. Ozdemir, K. Topaloglu, R. Gunes, S. Bayram, F. Alan, B. Albay, nurse; A. Arkovan, laboratory technician; U. Oz, medical secretary; E. Gediz employee for their contribution to data collection and to Handan Camdeviren Ankaral1, Assoc. Prof. for her help with statistical analyses.

\section{Ethics approval}

The research protocol was approved by the Ethics Commission of the Medical Faculty at Mersin University, and permission to conduct the study was obtained from local health authorities.

\section{Conflict of interests}

None declared

\section{REFERENCES}

1. World Health Organization. The Stop TB Strategy: building on and enhancing DOTS to meet the TB-related Millennium Development Goals. Geneva: WHO; 2006.

2. World Health Organization. Global Plan to Stop TB 2006-2015. Geneva: WHO; 2006.

3. World Health Organization. Global tuberculosis control: WHO report 2010. Geneva: WHO; 2010.

4. World Health Organization. The Global Plan to Stop TB 2011-2015: transforming the fight towards elimination of tuberculosis - reprinted with changes, 2011. Geneva: WHO; 2010.

5. World Health Organization. Global tuberculosis control: epidemiology, strategy, financing: WHO report 2009. Geneva: WHO; 2009.

6. World Health Organization. Compendium of indicators for monitoring and evaluating national tuberculosis programmes. Geneva: WHO; 2004.

7. Bozkurt H, Türkkani, Musaonbasioglu S, Güllü Ü, Baykal F, Hasanoglu C, et al., editors. Report on tuberculosis control in Turkey 2009 [Internet]. 
Ankara: The Ministry of Health of Turkish Republic; 2009 [cited 2010 Apr 22]. Available from: http://www.ehsm.gov.tr/Sub/verem savas dispanseri/files/dokumanlar/turkiyede-verem-savasi-2009-raporu.pdf. (In Turkish.)

8. Mersin statistics yearbook 2004. Mersin: The Ministry of Health of Turkish Republic; Local Health Authority of Mersin; 2004. (In Turkish.)

9. Mersin statistics yearbook 2005. Mersin: The Ministry of Health of Turkish Republic; Local Health Authority of Mersin; 2005. (In Turkish.)

10. Mersin statistics yearbook 2006. Mersin: The Ministry of Health of Turk ish Republic; Local Health Authority of Mersin; 2006. (In Turkish.)

11. Mersin statistics yearbook 2007. Mersin: The Ministry of Health of Turkish Republic; Local Health Authority of Mersin; 2007. (In Turkish.)

12. Mersin statistics yearbook 2008. Mersin: The Ministry of Health of Turkish Republic; Local Health Authority of Mersin; 2008. (In Turkish.)

13. Mersin, geography [Internet]. [cited 2010 Oct 21]. Available from: http:// www.mersinkulturturizm.gov.tr/belge/1-33665/cografya.html. (In Turkish.)

14. Bozkurt H, editor. Report on tuberculosis control in Turkey 2010 [Internet]. Ankara: The Ministry of Health of Turkish Republic; 2010 [cited 2011 Feb 02]. Available from: http://www.ehsm.gov.tr/Sub/verem savas_dispanseri/files/dokumanlar/turkiyede_verem_savasi_2010_raporu. pdf. (In Turkish.)

15. Gümüşlü F, Özkara Ş, Özkan S, Baykal F, Güllü Ü, editors; Report on tuberculosis control in Turkey 2007 [Internet]. Ankara: The Ministry of Health of Turkish Republic, Department of Tuberculosis Control; 2007 [cited 2010 Jun 23]. Available from: http://www.verem.org.tr/pdf/ verem savasi 2007 raporu.pdf. (In Turkish.)

16. Dye C, Lönnroth K, Jaramillo E, Williams BG, Raviglione M. Trends in tuberculosis incidence and their determinants in 134 countries. Bull World Health Organ. 2009 Sep;87(9):683-91.

17. Falzon D, van Cauteren D. Demographic features and trends in tuberculosis cases in the European Region, 1995-2005. Euro Surveill. 2008 Mar 18;13(12). pii: 8075 .

18. Balbay Ö, Ișıkhan V, Annakkaya AN, Arbak P, Bilgin C, Bulut I, et al. Social and economical aspects of tuberculosis patients in Turkey: a study with 733 patients in 23 chest disease hospitals. Düzce Medical Journal. 2004;(2):5-14. (In Turkish.)
19. Akgün M, Kaynar H, Sağlam L, Araz O, Ozden K, Yapanoğlu T, et al. Clinical and social characteristics of the patients with tuberculosis in Eastern Anatolia. Tuberk Toraks. 2006;54(4):349-54

20. Öztop A, Ünsal İ, Günay T, Özgü A, Cakmak R, Ucku R. The epidemiological characteristics of tuberculosis patients registered in Kahramanlar dispensary between 1999 and 2003. Solunum Hastaliklari. 2006;17(3):123-32. (In Turkish.)

21. Elbek O, Yardi AD, Uyar M, Tanriöver M, Börekçi S, Dikensoy O. The results of patients follow up at Gaziantep Number II Dispensary of Tuberculosis Control in the year 2004. Tuberk Toraks. 2006;54(4):341-8. (In Turkish.)

22. Calpe J, Chiner E, Marín J, Armero V, Calpe A. Tuberculosis epidemiology in area 15 of the Spanish autonomous community of Valencia: evolution from 1987 through 2001. Arch Bronconeumol. 2005 Mar;41(3):11824. (In Spanish.)

23. Iñigo J, Arce A, Palenque E, García de Viedma D, Chaves F. Decreased tuberculosis incidence and declining clustered case rates, Madrid. Emerg Infect Dis. 2008 Oct;14(10):1641-3.

24. Bierrenbach AL, Gomes AB, Noronha EF, Souza Mde F. Tuberculosis incidence and cure rates, Brazil, 2000-2004. Rev Saude Publica. 2007 Sep;41 Supp1 1:24-33. (In Portuguese.)

25. Chaimowicz F. Age transition of tuberculosis incidence and mortality in Brazil. Rev Saude Publica. 2001 Feb;35(1):81-7.

26. Kart L, Akduman D, Altin R, Tor M, Unalacak M, Begendik F, et al. Fourteen-year trend of tuberculosis dynamics in the northwest of Turkey. Respiration. 2003 Sep-Oct;70(5):468-74.

27. Marais BJ, Gie RP, Schaaf HS, Beyers N, Donald PR, Starke JR. Childhood pulmonary tuberculosis: old wisdom and new challenges. Am J Respir Crit Care Med. 2006 May 15;173(10):1078-90.

28. Tuberculosis Coalition for Technical Assistance. International Standards for Tuberculosis Care (ISTC). 2nd ed. The Hague: Tuberculosis Coalition for Technical Assistance; 2009.

29. Ditiu L. National Tuberculosis Programme in Romania 1997-2000: how it works. Cent Eur J Public Health. 1999 Nov;7(4):189-90.

Received August 17, 2011 Accepted in Revised form February 27, 2012 